\title{
ASSESSMENT OF COLLAGEN COATED POLYESTER FOUR-ARMED TRANSOBTURATOR MESH IN REPAIR OF ANTERIOR PELVIC ORGAN PROLAPSE. A PILOT STUDY
}

\author{
Hany Mostafa Abdallah, Ahmed Farouk Mahmoud, Hisham Abd- Elmajeed Fahim, \\ Hisham Ahmed Arafa
}

Department of Urology, Faculty of Medicine, Ain Shams University, Cairo, Egypt .Corresponding : Hisham Ahmed Arafa

Mobile: 01001921334

E mail:

hishamarafa1988@gmail.com

Received: $22 / 5 / 2019$

Accepted: 18/6/2019

\begin{abstract}
:
Background: Numerous techniques have been used during the last century to treat Pelvic organ prolapse, with varying success rates both for the abdominal and the vaginal route. Vaginal route for treatment of anterior POP using native tissue repair is associated with high relapse rates.
\end{abstract}

Aim of the work: To assess safety and efficacy of four-armed transobturator collagen coated polyester mesh in repair of cystocele.

Patients and Methods: 20 patients with stage II or more cystoceleaccording to Baden Walker classification system with or without SUI or apical prolapse were evaluated. They underwent cystocele repair trans-vaginally via tailored four-armed transobturator collagen coated polyester mesh.

Results: The mean follow-up time was $15.50 \pm 3.43$ month (Range, 12-24 month). The anatomical success rate was 100\% according to our definition to successful surgery which implies stage 1 or absence of anterior prolapse at follow up according to Badenwalker classification system. None of our patients developed mesh exposure all through their period of follow up.

Conclusion: Our study emphasizes that collagen coated polyester mesh use in transvaginal repair of anterior pelvic organ prolapse is safe and effective at least over a period of 12 month follow up.

Key Words: pelvic organ prolapse, synthetic mesh, mesh erosion,trocar-guided.

\section{INTRODUCTION:}

The most common procedure done for females above 70 years of age is pelvic organ prolapse repair ${ }^{1}$. Cystocele or anterior vaginal wall prolapse is the most common type of POP to be repaired in women $^{2}$.

Management of anterior POP has shown several shifts during the last years between the optimum procedures to be done $^{3}$. Native tissue repair is associated with high recurrence rate and paravaginal repair is not better to the traditional procedures as well ${ }^{4}$.

These high rates have led to a continuous search for more durable solutions in the surgical repair of POP. Several studies have been implemented for the use of synthetic meshes trans-vaginally for the repair of anterior prolapse inspired by satisfactory and promising results collected from their use in inguinal hernia ${ }^{5}$. 
Meanwhile, these encouraged enthusiasts for the use of non-absorbable meshes in clinical practice packed up by their low recurrence rates compared to native tissue repair. However, it was associated with multiple mesh-related adverse effects ${ }^{6}$.

In 2016, the FDA reclassified pre-cut commercially available mesh for transvaginal repair of pelvic organ prolapse from class II into class III (i.e. high risk) and required submission of premarket approval applications. The classification change was made in response to increased reporting of adverse events from meshbased transvaginal POP repairs ${ }^{7}$.

In 2019, the US Food and Drug Administration (FDA) banned the sale and distribution of surgical mesh for use in transvaginal anterior compartment prolapse (i.e., cystocele) repair because they were unable to confirm that the probable benefits outweighed the probable risks ${ }^{8}$.

While the 2019 National Institute for Health and Care Excellence (NICE) guidelines based on the benefit/risk ratio did not ban the use of prosthetic meshes for transvaginal prolapse repair. Instead, the organization advice use of a decision aid for women considering surgery, detailed counseling for women considering mesh-based procedures, and tracking of data on surgery and complications ${ }^{9}$.

These data revealed the rationale to be adopted for a new technique with low recurrence rates as well as avoidance of mesh-related complications associated with non-absorbable mesh use, so researches began for assessment of partially absorbable mesh. A prospective cohort study of 127 women treated with a trocarguided, partially absorbable mesh kit demonstrated favorable outcomes in efficacy and safety at 1 year follow up ${ }^{10}$.

\section{AIM OF THE WORK:}

To assess safety and efficacy of fourarmed transobturator collagen coated polyester mesh in repair of cystocele.

\section{PATIENTS AND METHODS:}

This was a pilot prospective study conducted on 20 patients with anterior POP over a period of 2 years and 3 months from March 2017 to June 2019. The study protocol was approved by the Urology Department of Ain Shams University review board and Faculty of Medicine Ain Shams University Research Ethics Committee (FMASU REC). Informed consents were obtained from all participants.

The study included 20 patients with stage II or more anterior POP according to Baden Walker classification system with or without SUI or apical prolapse.

Women were excluded if they have conditions that would compromise healing as on regular corticosteroid or any other immunosuppressive therapy, those who had undergone previous trans-obturator incontinence sling surgery or any other transvaginal surgery, those with cancer in the pelvic region or those who had associated posterior pelvic organ prolapse.

\section{Preoperative Evaluation:}

All patients underwent detailed history taking about medical,sexual, family and surgical history. Demographic features and medical history included age, occupation, body mass index (BMI), menopausal state, parity, and past history of previous urogynecological surgeries.

\section{The used mesh:}

The mesh used (Parietex composite mesh TM) is a multifilament, weaved, macroporous polyester prosthesis of density $78 \mathrm{gm} / \mathrm{m}^{2}$ reaching $38 \mathrm{gm} / \mathrm{m}^{2}$ after resorption, which is 
covered with an absorbable, continuous and hydrophilic film on one of its sides. This film is made up of a mix of collagen of porcine origin and glycerol.
Reshaping of the mesh takes place into a trapezoidal shape with four arms whose width could be manipulated according to the degree of cystocele as shown in figure.

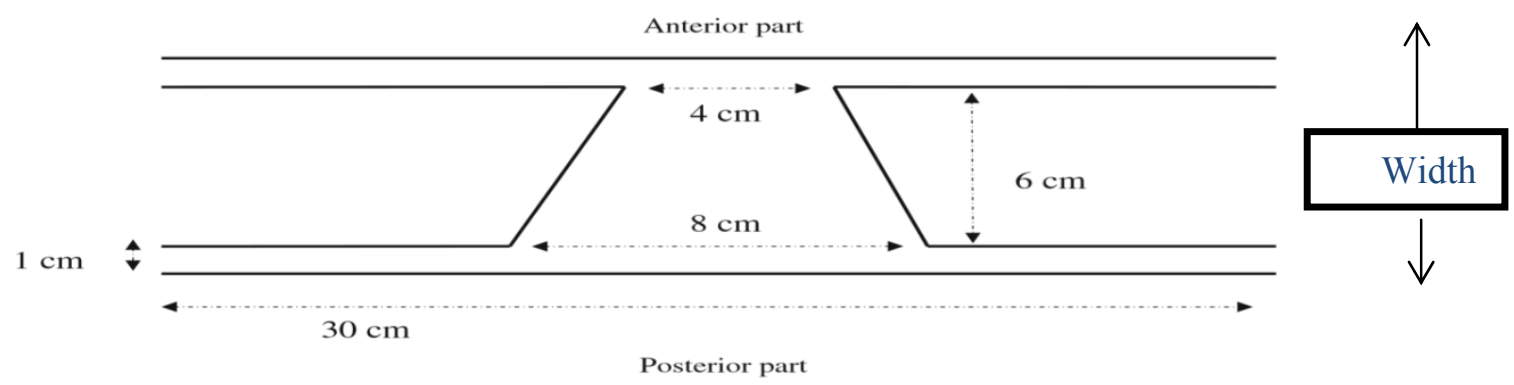

(Figure: diagrammatic view of the mesh)

The absorbable collagen layer is characterized by minimizedadherence to the surrounding tissues allowing time for vaginal mucosa to heal where host response towards the mesh used is characterized by being strong incorporation rather than inflammatory encapsulation in prospective and comparative animal studies decreasing incidence of mesh erosion into the adjacent visceral structures.

In an animal study comparing meshes with and without a protective barrier, collagen-protected meshes had significantly fewer visceral attachments than did the nonprotected meshes $(p<0.01)$, with complete recolonization of the mesh and film resorption after 45 days without any sign of shrinkage or wrinkling ${ }^{11}$.

\section{Surgical technique}

A midline partial thickness vertical incision including the vaginal mucosa and sparing the underlying fibromuscular stroma is performed on the anterior vagina extending from the bladder neck till the cervix. Then the bladder is dissected away from the vaginal wall. The para-vesical fossae are opened until the ischial spine and the arcus tendinous of the levatorani are reached.

Two skin incisions are made on both sides: anteriorly at the level of the clitoris just lateral to the ischiopubic ramus and posteriorly at the lowest part of the obturator foramen which is usually $1 \mathrm{~cm}$ lateral and 3 $\mathrm{cm}$ inferior to the former anterior incision, just above the ischium. Gloves are changed before the insertion of the synthetic mesh.

The two anterior arms of the trapezoidal shaped mesh are inserted with two helical trans-obturator needles through the anterior skin incisions with an outside inside transobturator technique, perforating soft tissue, obturator muscle, obturator membrane, and turning around the ischiopubic ramus, lateral to the bladder neck, aiming the finger positioned in the para-vesical fossae.

The same needles with the same technique are used for the insertion of the posterior arms. The external obturator muscles are perforated as close as possible to the ischium at the lowest part of the obturator membrane. Then, the blunt tip of the transobturator needles are further guided parallel to the internal obturator muscle in the direction of the ischial spine and the insertion of the arcus tendinous levatorani.

There, the internal obturator muscle and its fascia are perforated, and the tip of the needles led out of the vaginal incision. The posterior arms are threaded in and passed through the tunnel on both sides. 
The posterior arms are pulled in order to lay the mesh in the right position under the bladder, without excessive tension, creating sub-vesical hammock to treat the prolapse.

The central sheet of the mesh was placed underneath the bladder base in a tension-free manner so that the non-absorbable interface of the mesh is facing the bladder while the absorbable interface of the mesh is facing the vagina.

Caution should be made to avoid folding or crumbling of the mesh to avoid vaginal shrinkage and vaginal erosion by tailoring the width of the mesh so that it fits the patient and is not too large to just support the defect.

The mesh is sutured at the proximal and distal edges to the cervix and bladder neck by use of 2-0 separate vicryl sutures to keep the mesh in place and avoid migration or folding of the mesh. The arms were placed under gentle traction from both sides to adjust the elevation of the bladder. The extra lengths of the arms were cut at the level of the groin incisions.

Finally, the vaginal epithelium is sutured with interrupted sutures vicryl 2.0, closing the fascia at the same time and a vaginal pack is inserted at the end of the procedure.

If the patient has SUI (10 patients) a mid-urethral sling was placed through a different vaginal incision to avoid mesh migration and if there is an associated apical POP a unilateral sacrospinous fixation was done ( 6 patients) from the same incision after exposure of the sacrospinous ligament by use of the Capio device in 4 patients and via Miya hook in 2 patients.

\section{Postoperative care and follow up:}

Patients will be re-evaluated during their hospital stay, 1 week, 6 weeks, 6 months, and 1 year after surgery as regard anatomical and functional outcome.

Anatomical outcome will be done by reassessment using Baden Walker classification system of POP during the postoperative follow-up with "Anatomical cure" will be defined as having a stage 0 or stage I cystocele after the follow up period.

While the functional outcome includes questions concerning patient satisfaction, urinary dysfunction including incontinence or retention, quality of life, mesh exposure, vaginal bulge, dyspareunia, and vaginal pain.

\section{RESULTS:}

The demographic data is given in the table as the study included 20 patients where none of our patients required reoperation whether for recurrence of prolapse or for vaginal erosion or any other condition necessitating reoperation over a mean period of follow up of $15.50 \pm 3.43$ month (Range, 12-24 month).

Cystocele was stages IV, III and II in two $(10 \%)$, ten $(50 \%)$ and eight $(40 \%)$ patients respectively. In one of the 2 patients diagnosed as grade IV cystocele intraoperative hysterectomy was done. 


\begin{tabular}{|l|l|c|}
\hline \multicolumn{2}{|c|}{} & Total no. $=\mathbf{2 0}$ \\
\hline \multirow{2}{*}{ Age } & Mean \pm SD & $45.75 \pm 10.88$ \\
\cline { 2 - 3 } & Range & $34-80$ \\
\hline \multirow{2}{*}{ Parity } & Median (IQR) & $3(3-4)$ \\
\cline { 2 - 3 } & Range & $2-8$ \\
\hline \multirow{2}{*}{ Menual activity } & Active & $13(65.0 \%)$ \\
\cline { 2 - 3 } & Inactive & $7(35.0 \%)$ \\
\hline \multirow{2}{*}{ BMI } & Menopausal & $10(50.0 \%)$ \\
\cline { 2 - 3 } & Menstruating & $10(50.0 \%)$ \\
\hline \multirow{3}{*}{ Medical history } & Mean \pm SD & $30.65 \pm 3.88$ \\
\cline { 2 - 3 } & Range & $22-38$ \\
\hline \multirow{2}{*}{ Family history of POP } & Free & $17(85.0 \%)$ \\
\cline { 2 - 3 } & Cardiac & $2(10.0 \%)$ \\
\cline { 2 - 3 } & Diabetic hypertensive & $1(5.0 \%)$ \\
\cline { 2 - 3 } & Positive & $7(35.0 \%)$ \\
\cline { 2 - 3 } & Negative & $13(65.0 \%)$ \\
\hline
\end{tabular}

(Table: demographic data of patients)

Six of 20 patients $(30 \%)$ had simultaneous vaginal vault prolapse for which unilateral sacrospinous fixation was done in the same session. None of our women had posterior vaginal wall prolapse as well.

Associated sub urethral sling (tension free TOT) was applied in ten patients $(50 \%)$ following the cystocele repair for patients suffering from evident SUI or occult SUI which appears after preoperative prolapse reduction stress test.

It was done in the same operative session through a separate vaginal incision to overcome risk of displacement.

The operative time ranged from 30 to 120 minutes with mean 58.40 and standard deviation 26. However, operative time for patients who underwent anterior POP repair with the four-armed mesh as a soul operation ranges from 30 to 70 minutes with mean 45.38 and standard deviation 16.89 .

The amount of blood loss ranged from 30 to $200 \mathrm{ml}$ with mean $106.00 \pm 52.4$. And there was no documentation of any vascular or neurological injury on top of passage of the trans-obturator needles.
There was no visceral organ injury in any of our cases.

All patients were discharged to home after removal of vaginal pack and urethral catheter 48 hours post-operatively; only 1 patient needed hospital stay for 9 days for follow up of urinary retention which was expressed in the form of failure to void after urethral catheter removal 48 hours post-operative.

So another urethral catheter was reapplied and patient was subjected to proper analgesic and anti-edematous drugs followed by a second trial to void one week later which was successful and her postvoiding residual was zero.

Three patients complained of groin pain that required 1,3 and 5 month time of analgesic treatment. Where there was no significant positive correlation with any of the pre-operative data (age, parity, sexual activity or menopausal status) or intra-operative procedures done or with the length of the operation or estimated blood loss intraoperatively.

Although being statistically insignificant, it was noted that mean BMI was lower for patients who developed groin pain $(28 \pm 5.29$ $\left.\mathrm{kg} / \mathrm{m}^{2}\right)$ when compared to that $(31.12 \pm 3.59$ 
$\mathrm{kg} / \mathrm{m}^{2}$ ) of patients free from groin pain. However, this may be significant if the study population was larger.

Only one patient out of 13 sexually active females complained of de novo dyspareunia although there was no evidence of vaginal shortening or vaginal erosion. However, this de novo dyspareunia may be attributed to vaginal dryness and patient was advised to use vaginal lubricants and estrogen vaginal cream.

None of our patients developed postoperative hemorrhage or hematoma formation, wound infection or abscess formation or persistence of preoperatively evident SUI.

18 out of the 20 patients included in the study was satisfied with the procedure during their follow up 12 month after surgery, one patient was not satisfied because of unmasking SUI which was not evident pre-operatively while the cause in the second patient was the appearance of de novo dyspareunia.

\section{DISCUSSION:}

It is a matter of debate which mesh is optimally used in repair of anterior POP with the characteristics that give satisfactory anatomical cure rate and less incidence of mesh exposure. Several studies have been implemented upon different partially absorbable meshes with different characteristics revealing different incidence of mesh exposure and anatomical cure rates ${ }^{10,12,13,14,15}$.

In our study we used polyester collagen coated mesh (Parietex $\left.{ }^{\circledR}\right)$ which is tailored for each patient separately to adjust her need without folding. While it has not been used previously in trans-vaginal repair of anterior POP, it was used in laparoscopic sacrocolpopexy with satisfactory outcome $^{16}$.
Most of the authors agreed to consider successfulness of the repair in absence of POP (grade 0) or in the presence of grade I POP on physical examination as grade I do not need further intervention. So recurrence of POP or failure of the procedure means the presence of grade II or higher on follow up of the patients. Our preliminary results were satisfactory as there were no incidence of mesh erosion and anatomical cure rate of $100 \%$ over a period of follow up ranging from 12-24 month.

In our study mesh exposure was not seen in any out of 20 women $(0 \%)$. In a series comparing non-absorbable polypropylene mesh to native tissue repair after 1 year followup, an exposure rate of the mesh group $11.3 \%$ was reported and re-operation for management of mesh exposure was $7 \%$.

In the last review implemented by the Cochrane database, 37 studies were included, 25 of which was using non-absorbable mesh as a prosthetic material of their study, 3 on totally absorbable ones and 10 on biological graft. However, there was not a single study on partially absorbable meshes use ${ }^{17}$.

The low exposure rates in partially absorbable mesh may be delegated to many reasons including, the assumed benefit against a harmful exaggerated inflammatory response, host integration, and satisfactory repair as well as well as their low weight after resorption of the absorbable material resulting in a more physiological integration of the mesh.

In our study the mean operative time 58.4 min (range: 30-120 minutes). However, operative time for patients who underwent anterior POP repair with the four-armed mesh as a soul operation ranges from 30 to 70 minutes with mean 45.38 and standard deviation 16.89. This longer operative time in our study when compared with previous ones may be attributed to the time taken for fashioning of the mesh in its trapezoidal shape $^{13}$.

In conclusion, partially absorbable meshes could potentially be a promising choice for 
further research and studies, as there was no failure in our patients in addition there was no cases of mesh erosion.

After1-year follow-up, the anatomical success rate was significantly in favor of use of composite mesh in repair of anterior POP. In our opinion, these observations support the clinical value of longer periods of follow-up in POP trials.

\section{REFERENCES:}

1. Oliphant SS, Jones KA, Wang L, Bunker CH, Lowder JL. (2010): Trends over time with commonly performed obstetric and gynecologic inpatient procedures. ObstetGynecol 2010; 116:926.

2. Rane A, Iyer J, Kannan K, Corstiaans A. (2012): Prospective study of the Perigee ${ }^{\mathrm{TM}}$ system for treatment of cystocele - our five-year experience. Aust $\mathrm{N} \quad \mathrm{Z} \quad \mathrm{J}$ ObstetGynaecol; 52:28-33.

3. Keys T, Campeau L, Badlani G. (2012): Synthetic mesh in the surgical repair of pelvic organ prolapses: current status and future directions. Urology; 80:237-43.

4. Moore RD, Beyer RD, Jacoby K, Freedman SJ, McCammon KA, Gambla MT. (2010): Prospective multicenter trial assessing type I, polypropylene mesh placed via transobturator route for the treatment of anterior vaginal prolapse with 2-year follow-up. IntUrogynecol J; 21:545-52.

5. Weber A.M., Walters M.D., Piedmonte M.R., Ballard L.A. (2001): Anterior colporrhaphy: a randomized trial of three surgical techniques. Am J ObstetGynecol; 185:1299-1306.

6. Altman D, Väyrynen $\mathrm{T}$, Engh ME, Axelsen S, Falconer C, (2011): Anterior colporrhaphy versus transvaginal mesh for pelvic-organ prolapse. $\mathrm{N}$ Engl $\mathrm{J}$ Med.;12:1826-36.

7. Information for health care providers for stress urinary incontinence. US Food and Drug Administration. January 2016. http://www.fda.gov/MedicalDevices/Prod
uctsandMedicalProcedures/ImplantsandProsth etics/UroGynSurgicalMesh/ucm345221.htm (Accessed on January 12, 2016).

8. Urogynecologic Surgical Mesh Implants. U.S. Food and Drug Administration. April 2019. http://www.fda.gov/Medicalevices/

Productsand Medical Procedures/Implants and Prosthetics/Uro Gyn Surgical Mesh/ default.htm (Accessed on April 18, 2019).

9. Urinary incontinence and pelvic organ prolapse in women: management. NICE guideline. National Institute for Health and Care Excellence. April 2019. www. nice. org.uk/guidance/ng123/resources/urinary incontinence-and-pelvic-organ-prolapse- inwomen-management-pdf-66141657205189 (Accessed on April 22, 2019).

10. MilaniAL, HinoulP, Gauld JM, Sikirica V, vanDrieD,CossonM, (2011): Trocar-guided mesh repair of vaginal prolapse using partially absorbable mesh: 1 year outcomes. Am J Obstet Gynecol.; 204(1):74.

11. Benchetrit S., Debaert M., Detruit B., Dufilho A., Gaujoux D., Lagoutte J., Lepere M, Saint Leon LM, d'Escurac XP, Rico E, Sorrentino J. (1998): Laparoscopic and open abdominal wall reconstruction using Parietex ${ }^{\mathrm{TM}}$ meshes Clinical results in 2700 hernias. Hernia, 2(2), $57-62$.

12. Niesel A. ,Gramalla O. , RohneA. (2008): A preliminary report on the use of a partially absorbable mesh in pelvic reconstructive surgery. Journal of Pelviperineology, 27: 2225.

13. Cervigni M, Natale F, La Penna C, Saltari M, Padoa A, Agostini M. (2011): Collagencoated polypropylene mesh in vaginal prolapse surgery: an observational study. Eur J ObstetGynecolReprod Biol;156(2):223-7.

14. Lo, T.-S., Tan, Y. L., Khanuengkitkong, S., Dass, A. K., Cortes, E. F. M., \& Wu, P.-Y. (2014): Assessment of Collagen-Coated Anterior Mesh through Morphology and Clinical Outcomes in Pelvic Reconstructive Surgery for Pelvic Organ Prolapse. Journal of Minimally Invasive Gynecology, 21(5), 753761.

15. Quemener J., Joutel N., Lucot J.-P., Giraudet G., Collinet P., Rubod C., \&Cosson M. 
(2014): Rate of re-interventions after transvaginal pelvic organ prolapse repair using partially absorbable mesh: 20 months median follow-up outcomes. European Journal of Obstetrics \& Gynecology and Reproductive Biology, 175, 194-198.

16. Sergent F., Resch B., Loisel C., Bisson V., Schaal J., Marpeau L. (2011): Mid-term outcome of laparoscopic sacrocolpopexy with anterior and posterior polyester mesh for treatment of genito-urinary prolapse European Journal of Obstetrics \& Gynecology and Reproductive Biology; 156, 217-222.

17. Maher C, Feiner B, Baessler K, et al. (2016): Surgery for women with anterior compartment prolapse. Cochrane Database Syst Rev; 11:CD004014.

\section{تقييم شبكه البولي ايستر المغلفة بالكو لاجين ذات الاربع ازرع في إصلاح السقوط المهبلي الأمامي من

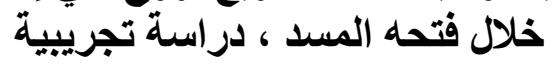

هاني مصطفى عبد الله و احمد فاروق محمود سالم و هثام عبد المجيد فهيم و هثام احمد عبد الحميد عرفه

$$
\text { قسم جرحه المسالك البوليه - كليه الطب - جامعه عين شمس }
$$

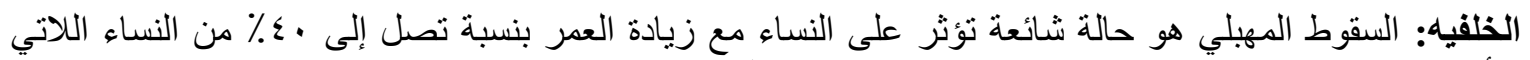

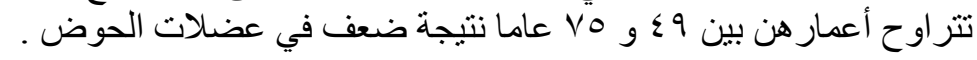

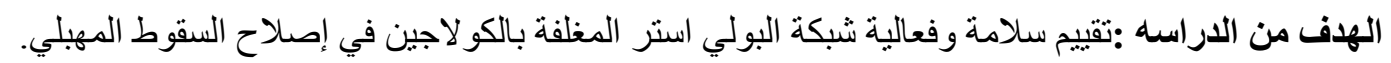

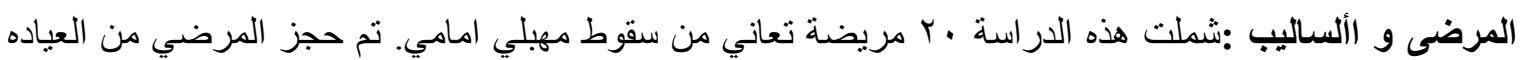

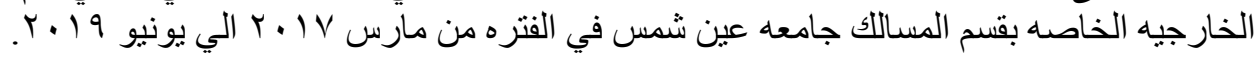

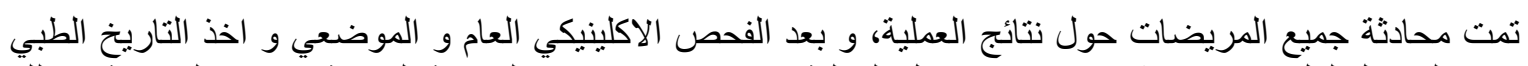

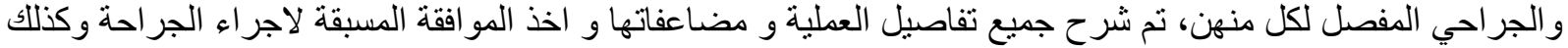
تم تركيب شبكه البولي استر المغلفه بالكو لاجين لاصدلاح السقوط المهبلي الامامي.

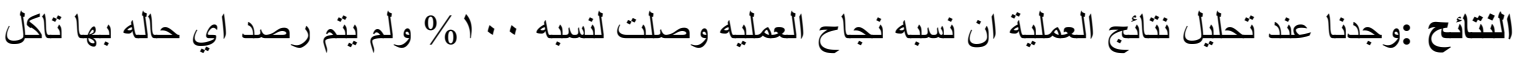

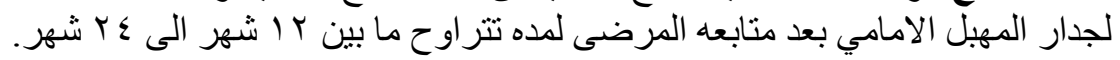

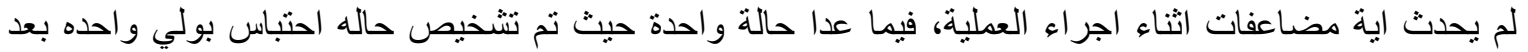

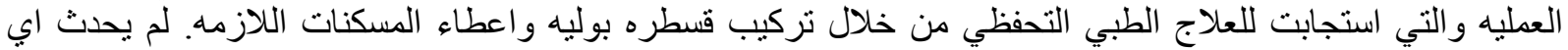
حالات عدوي بالجهاز البولي ولم يكن هناك احتياج لنقل دم لاي حالة تلاكي

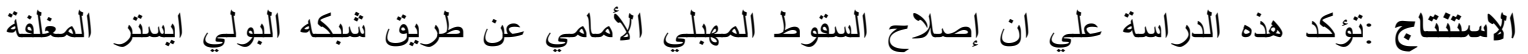

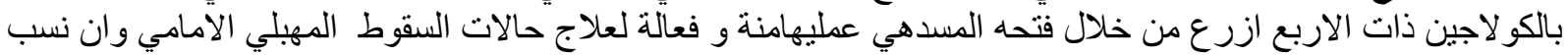

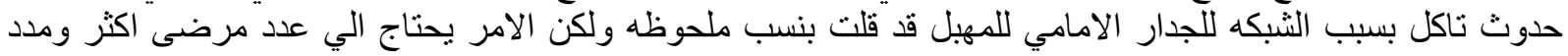
متابعه اكبر لتقييم الثبكه على المدى الطويلي. 